\title{
Cellular Requirements for Antigen Processing by Antigen- Presenting Cells: Evidence for Different Pathways in Forming the Same Antigenic Determinants ${ }^{1}$
}

\author{
KIL-Hyoun Kim, MaXine J. Solvay, And David W. Thomas \\ Department of Microbiology and Immunology, University of Michigan \\ Medical School, Ann Arbor, Michigan 48109
}

Received May 21, 1985; accepted July 25, 1985

\begin{abstract}
In this report we examined the antigen-presenting cell (APC) requirements for activation of T-cell hybridomas specific for the protein antigen PPD (purified protein derivative of tuberculin). During the course of these studies we observed that glutaraldehyde fixation of la-positive A20.2JAD (A20) and P388D1 stimulator cells had different effects on T-cell activation. A20 cells fixed with glutaraldehyde stimulated the T cells in the presence of PPD as efficiently as nonfixed A20 cells. By contrast, glutaraldehyde treatment of Ia-positive P388D1 cells dramatically inhibited their ability to process and/or present PPD to $T$ cells. This was not due to nonspecific effects on the P388D1 cells since cells prepulsed with PPD prior to glutaraldehyde treatment stimulated T cells as efficiently as non-glutaraldehyde-treated P388DI cells. In addition, there was no apparent difference in "fixing" of the two cell types as determined by the uptake of radiolabeled thymidine. These observations suggested that P388D1, but not A20, cells required PPD internalization to form the relevant antigenic determinants. This was substantiated by showing that treatment of P388DI cells with chloroquine prior to PPD pulsing eliminated their stimulatory capacity, but had no effect on P388D1 cells previously pulsed with PPD. Chloroquine treatment had no effect on stimulation by A20 cells. Since PPD internalization appeared not to be required for presentation by $A 20$ cells, we next determined if isolated $A 20$ plasma membranes would substitute for the intact cell. We observed that the isolated plasma membranes from PPD-pulsed A20 cells stimulated the $T$ hybridoma cells, and that this stimulation was antigen-specific and was inhibited by antiIa monoclonal antibodies. Taken together, the results presented here suggest that for the PPDspecific T-cell responses examined here, different APC utilize distinct pathways to present the same antigenic determinant for T-cell recognition. 1985 Academic Press, Inc.
\end{abstract}

\section{INTRODUCTION}

The mechanism(s) by which antigen-presenting cells (APC) ${ }^{2}$ form antigenic determinants from foreign antigens that are recognized by $T$ cells has generally been called antigen processing or antigen handling. This mechanism is only beginning to be elucidated, and seems to involve several elements. For larger proteins, one initial event appears to be antigen internalization and subsequent catabolism to smaller peptide

\footnotetext{
' This work was supported by U.S. Public Health Service Grant AI-19273 from the National Institute of Allergy and Infectious Diseases.

${ }^{2}$ Abbreviations used: APC, antigen-presenting cells; CAS, culture supernatant fluid from concanavalin A activated spleen cells; IL-2, interleukin 2; HBSS, Hanks' balanced salt solution; PPD, purified protein derivative of tuberculin; PBS, phosphate-buffered saline; PMSF, phenylmethylsulfonyl fluoride.
} 
fragments, which form the antigen actually recognized by $\mathrm{T}$ cells $(1-5)$. These results are based primarily on experiments in which agents that inhibit lysosomal proteolysis block formation of the relevant antigen, and on fixing the APC with glutaraldehyde or paraformaldehyde to prevent antigen internalization and formation of the antigenic fragment. If smaller hapten or peptide antigens are used, then there seems to be no requirement for internalization and fixed APC present antigen as efficiently as untreated APC $(1,2,6)$. In the case of small peptide antigens, APC membrane structures associate with the peptides and retain the antigen to be utilized in T-cell responses (7). It has been assumed that the antigen recognized by $T$ cells is associated with the APC membrane, and that isolated membranes from antigen-pulsed APC provide a source of antigen for T-cell responses $(2,7)$. However, T-cell stimulation with isolated membranes has generally required additional APC, suggesting that the membranes are processed and the antigen presented only in the context of the APC, and that it is not direct Tcell recognition of the membrane-associated antigen [(2); unpublished observations].

In this report we have examined the effects of glutaralydehyde treatment on presentation of protein antigen to the same murine T-cell hybridoma by different APC. It was found that presentation of the same antigen to the same $T$ cells by two different APC showed a dramatic difference in the effects of glutaraldehyde fixation and chloroquine treatment. These results suggest that proteolytic processing enzymes may have different cellular locations in different APC, and/or that APC may have unique mechanisms for antigen handling. In addition, it is also shown that isolated membranes from PPD-pulsed A20 specifically activate T-cell hybridomas in the absence of additional APC, thus providing direct evidence that the APC events involved in T-cell recognition are all membrane-associated and do not require intact cells.

\section{MATERIALS AND METHODS}

\section{T-Cell Hybridomas}

T-Cell hybridomas were prepared as described elsewhere $(8,9)$. Briefly, Bab. 14 $\left(H-2^{d}\right)$ mice were immunized with complete Freund's adjuvant (Difco Laboratories, Detroit, Mich.), and the popliteal lymph nodes were removed 2 weeks later. The lymph node cells were cultured with $50 \mu \mathrm{g} / \mathrm{ml}$ PPD (Connaught Medical Research Labs, Ontario, Canada) at $2.5 \times 10^{6}$ cells $/ \mathrm{ml}$ in RPMI 1640 medium (M.A. Bioproducts, Walkersville, Md.) containing $300 \mu \mathrm{g} / \mathrm{ml}$ glutamine (KC Biological, Lenexa, Kans.), $5 \times 10^{-5} M$ 2-mercaptoethanol (Bio-Rad Laboratories, Richmond, Calif.), and $10 \%$ heat inactivated fetal calf serum (Hyclone Laboratories, Logan, Utah) for 3 days, and the blast cells were harvested by centrifugation on Ficoll-Hypaque (Sigma Chemical Co., St. Louis, Mo.). The blasts were cultured for an additional 2 days at 1 to $2 \times 10^{5}$ cells $/ \mathrm{ml}$ in medium containing $25 \%$ supernatant fluid from concanavalin A (Con A, Miles-Yeda International, Elkhart, Ind.)-stimulated rat spleen cells (CAS) and $0.1 \% \alpha$-methylmannoside (Sigma Chemical Co.). The resulting blast cells were fused with BW5147 cells (a generous gift from Dr. Ethan Shevach, Laboratory of Immunology, NIH) by established procedures $(8,9)$.

The resulting hybridomas were screened with Balb/c spleen cells and $50 \mu \mathrm{g} / \mathrm{ml}$ PPD for IL-2 production as described below. Those hybrids that showed PPD-specific IL-2 production were further subcloned by limiting dilution. The PPD-specific T hybridomas showed genetic restrictions for $\mathrm{I}-\mathrm{A}^{\mathrm{d}}$ and stimulation could be specifically blocked by anti-Ia ${ }^{d}$ monoclonal antibodies, such as M5/114.15.2 (American Type 
Culture Collection, Rockville, Md.). The T-cell hybridomas were maintained in Dulbecco's modificd Eagle medium (M.A. Bioproducts, Walkersvillc, Md.) containing glutamine, penicillin-streptomycin, 2-mercaptoethanol, 10\% nutrient cocktail (10), hypoxanthine, aminopterin, thymidine, and 15\% heat-inactivated FCS.

\section{Antigen-Presenting Cell Treatment}

APC used in these experiments were the Ia ${ }^{d}$-positive B-cell lines A20.2JAD (a generous gift from Dr. Philippa Marrack, National Jewish Hospital, Denver, Colo.) and the macrophage-like cell line P388D1 (from Dr. P. Marrack). The P388D1 were induced to express Ia ${ }^{d}$ antigens as described before (11) by culture for 2 days in $25 \%$ supernatant fluid from ConA-stimulated rat spleen cells (CAS) and $0.1 \% \alpha$-methylmannoside. Uninduced P388D1 showed some Ia expression by radioimmunoassay which was increased 5- to 10-fold after induction with CAS. Antigen-pulsed A20 or Ia-positive P388D1 cells were prepared by 2-hr culture in the presence of PPD at 200 $\mu \mathrm{g} / \mathrm{ml}$, and by washing them three times with Hanks' balanced salt solution (HBSS) to remove free PPD.

For glutaraldehyde fixation, cells were washed in phosphate-buffered saline (PBS, $\mathrm{pH}$ 7.2) and treated by mixing for $15 \mathrm{sec}$ with glutaraldehyde (Sigma Chemical Co.) in desired concentrations in PBS. The reaction was terminated by addition of excess PBS containing $0.1 \%$ glycine (Sigma Chemical Co.), and the cells were washed three times in HBSS prior to being used as APC. For chloroquine treatment, Ia-positive APC were treated with $600 \mu M$ chloroquine for $45 \mathrm{~min}$ at $37^{\circ} \mathrm{C}$ either before or after PPD pulsing, as described elsewhere (12).

\section{Preparation of Plasma Membranes from Antigen-Presenting Cells}

The A20 cells from which the plasma membranes were isolated, either untreated or pulsed overnight with PPD (200 $\mu \mathrm{g} / \mathrm{ml})$, were washed three times with HBSS and resuspended in HBSS containing $10 \mu \mathrm{g} / \mathrm{ml}$ of phenylmethylsulfonyl fluoride (PMSF, Sigma Chemical Co.). The cells were disrupted in a cell disrupter (Stansted Fluid Power Ltd., Esscx, England), using an aperture setting that sheared only the plasma membranes from the surface of the cell while leaving the nucleus and much of the cytoplasm intact. The sheared cells were centrifuged at $1500 \mathrm{rpm}$ for $10 \mathrm{~min}$ at $4{ }^{\circ} \mathrm{C}$ to remove nuclei and cells, and then the supernatant fluid was centrifuged at 5500 $\mathrm{rpm}$ for $15 \mathrm{~min}$ in a Sorvall RC-2B centrifuge at $4^{\circ} \mathrm{C}$ to remove subcellar organelles. The supernatant fluid from the 5500 -rpm centrifugation was collected and centrifuged again at $16,000 \mathrm{rpm}$ for $40 \mathrm{~min}$ at $4^{\circ} \mathrm{C}$, and the resulting crude plasma membrane pellet was resuspended in sterile $\mathrm{PBS}$ and stored at $-70^{\circ} \mathrm{C}$ until used.

\section{T-Cell Stimulation Culture and Assay for Interleukin 2 Production}

PPD-specific T hybridoma cells $\left(2 \times 10^{5}\right.$ cells/well) were cultured with $1 \times 10^{5} \mathrm{Ia}-$ positive P388D1 cells or $2 \times 10^{5} \mathrm{~A} 20.2 \mathrm{JAD}$ cells in hybridoma maintenance medium. No antigen or $10 \mu \mathrm{g} /$ well of soluble PPD was added to the cultures. After $20 \mathrm{hr}$ of culture the supernatant fluid was removed and assayed for interleukin 2 (IL-2) with IL-2 dependent HT-2 cells (a generous gift from Dr. Ethan Shevach) as described clscwhere $(8,9,13)$. The greatest dilution of supernatant fluid maintaining $>90 \%$ HT2 viability was the end point scored and the results were expressed as IL-2 units $/ \mathrm{ml}$. 


\section{RESULTS}

During the course of our studies on antigen processing and presentation by APC cells for T-cell activation, we noticed that Ia-positive A20.2JAD (A20) and P388D1 cells showed a differential sensitivity to glutaraldehyde fixation. Ia-positive P388DI cells fixed with glutaraldehyde in concentrations higher than $0.025 \%$ did not stimulate PPD-specific T hybridoma cells in the presence of soluble PPD (Table 1), and the T cells were stimulated only slightly by P388D1 cells fixed with $0.0125 \%$ glutaraldehyde. On the other hand, A20 cells remained active in stimulating $T$ hybridomas in the presence of PPD even though the cells were fixed with glutaraldehyde at concentrations of up to $0.05 \%$ (Table 1). One implication of these results is that A20 cells do not require PPD internalization for processing, or that antigen presentation may not require any processing event to present PPD to $T$ hybridomas. A less likely possibility may be that the A20 cells might not be fixed efficiently enough to block uptake of PPD, despite other published reports to the contrary (1). To examine this, A20 and P388D1 cells were fixcd with glutaraldchydc at varying concentrations and examincd for their capability to take up extracellular materials from the medium using $\left[{ }^{3} \mathrm{H}\right]$ thymidine. As shown in Table 2, fixation with glutaraldehyde in concentrations of $0.0125 \%$ or higher blocked the uptake of $\left[{ }^{3} \mathrm{H}\right]$ thymidine efficiently $(>95 \%)$ in A20 cells as well as P388D1 cells.

Another possibility to be considered is that the failure to stimulate $\mathrm{T}$ hybridomas by P388D1 cells fixed with glutaraldehyde might result from damage to other surface structures of the cells involved in stimulation, rather than direct interference with antigen processing. To examine this, we prepared Ia-positive P388D1 cells pulsed with PPD prior to and after fixing with glutaraldehyde to determine the nonspecific effects of glutaraldehyde on stimulation. The results shown in Table 3 clearly indicate that PPD-pulsed P388D1 were not sensitive to subsequent glutaraldehyde fixation, and were able to stimulate $T$ hybridomas. To rule out the possibility that glutaraldehyde

\section{TABLE 1}

Ability of Glutaraldehyde Fixed Antigen-Presenting Cells to Stimulate Antigen-Specific T Hybridoma Cells

\begin{tabular}{|c|c|c|}
\hline \multirow{2}{*}{$\begin{array}{c}\% \text { Glutaraldehyde } \\
\text { treatment }^{a}\end{array}$} & \multicolumn{2}{|c|}{$\begin{array}{c}\text { IL-2 Units/ml }{ }^{c} \\
\text { Stimulator cell type }\end{array}$} \\
\hline & $\mathrm{A} 20.2 \mathrm{JAD}$ & Ia-positive $\mathrm{P} 388 \mathrm{D} 1^{b}$ \\
\hline 0 (no antigen) & $<20$ & $<20$ \\
\hline 0 & 160 & 320 \\
\hline 0.0125 & 320 & 80 \\
\hline 0.025 & 320 & $<20$ \\
\hline 0.0375 & 320 & $<20$ \\
\hline 0.05 & 160 & $<20$ \\
\hline
\end{tabular}

\footnotetext{
a Ia-positive P388D1 or A20.2JAD cells were treated with glutaraldehyde at the concentration indicated, and then added to culture with $10 \mu \mathrm{g} /$ well PPD for stimulation of PPD-specific $\mathrm{T}$ hybridomas.

${ }^{b}$ P388D1 cells were induced for la expression by culture for a day in CAS.

${ }^{c}$ Units per milliliter of IL-2 contained in the culture supernatant fluids of each culture were determined as described under Materials and Methods. IL-2 activity in culturc without antigen was less than 20 units $/ \mathrm{ml}$.
} 
TABLE 2

Ability of Glutaraldehyde-Fixed Cells to Take up $\left[{ }^{3} \mathrm{H}\right]$ Thymidine

\begin{tabular}{|c|c|c|}
\hline \multirow[b]{2}{*}{$\begin{array}{l}\text { \%Glutaraldehyde } \\
\text { treatment }{ }^{a}\end{array}$} & \multicolumn{2}{|c|}{$\begin{array}{c}\text { Uptake of } \\
{\left[{ }^{3} \mathrm{II}\right] \text { thymidinc }(\mathrm{cpm})^{b}}\end{array}$} \\
\hline & $\mathrm{A} 20.2 \mathrm{JAD}$ & $\begin{array}{l}\text { Ia-positive } \\
\text { p388DI }\end{array}$ \\
\hline 0 & $15,996 \pm 2681$ & $14,349 \pm 1612$ \\
\hline 0.0125 & $672 \pm 251$ & $474 \pm 267$ \\
\hline 0.025 & $530 \pm 367$ & $272 \pm \quad 78$ \\
\hline 0.0375 & $730 \pm 361$ & $257 \pm 12$ \\
\hline 0.05 & $452 \pm 81$ & $17 \pm \quad 24$ \\
\hline
\end{tabular}

${ }^{a}$ Cells were treated with glutaraldehyde as described under Materials and Methods.

${ }^{b}$ Glutaraldehyde-fixed or intact cells were incubated with $1 \mu \mathrm{Ci}$ of $\left[{ }^{3} \mathrm{H}\right]$ thymidine for $4 \mathrm{hr}$ at $37^{\circ} \mathrm{C}$. Cells were harvested by an automatic cell harvester, and the cell-bound counts per minute were determined. Each value represents the average counts per minute and standard error from triplicate cultures.

only makes processing less efficient on la-positive P388DI cells, we determined if increasing the amount of PPD overcomes the inhibition caused by glutaraldehyde treatment. It was observed, however, that increasing the PPD concentration up to $2 \mathrm{mg} / \mathrm{ml}$ failed to stimulate in the presence of glutaraldehyde-treated Ia-positive P388D1 cells. In addition, increasing the concentration of glutaraldehyde-treated P388D1 cells to $1 \times 10^{6} /$ well also did not result in T-cell stimulation, ruling out that glutaraldehydeinduced inhibition could be overcome by adding more cells (data not shown).

Based on the above results, the most likely explanation for these results is that P388D1, but not A20, cells internalize the PPD to form the relevant antigenic deter-

\section{TABLE 3}

Stimulation of T Hybridoma Cells by Ia-Positive P388DI Cells Fixed with Glutaraldehyde before or after Exposure to PPD

\begin{tabular}{lcc}
\hline & \multicolumn{2}{c}{$\begin{array}{c}\text { IL-2 units/ml } \\
\text { Ia-positive P388D1, fixed }\end{array}$} \\
\cline { 2 - 3 } $\begin{array}{c}\text { \% Glutaraldehyde } \\
\text { treatment }\end{array}$ & $\begin{array}{c}\text { Before exposure } \\
\text { to PPD }\end{array}$ & $\begin{array}{c}\text { After exposure } \\
\text { to PPD }\end{array}$ \\
\hline 0 & 640 & 640 \\
0.0125 & 20 & 320 \\
0.025 & $<20$ & 320 \\
0.0375 & $<20$ & 320 \\
0.05 & $<20$ & 160 \\
\hline
\end{tabular}

${ }^{a}$ CAS-induced la-positive P388D1 cells were fixed with glutaraldehyde in the concentration of 0 to $0.05 \%$, and then incubated with $200 \mu \mathrm{g} / \mathrm{ml}$ PPD for $2 \mathrm{hr}$ at $37^{\circ} \mathrm{C}$, washed, and added to T hybridoma for stimulation.

${ }^{b}$ CAS-induced Ia-positive P388D1 cells were incubated with $200 \mu \mathrm{g} / \mathrm{ml} \mathrm{PPD} \mathrm{for} 2 \mathrm{hr}$ at $37^{\circ} \mathrm{C}$, washed, and then fixed with glutaraldehyde in the concentration of 0 to $0.05 \%$, and added to $\mathrm{T}$ hybridoma for stimulation. 
minant. Other studies have indicated that this internalization is required for lysosomal catabolism and that antigen processing can be blocked by reagents such as chloroquine. As shown in Table 4, chloroquine treatment of Ia-positive P388D1 cells before PPD pulsing dramatically interfered with stimulation, whereas treatment after PPD pulsing had little inhibitory effect. Chloroquine treatment of A20 cells before or after PPD pulsing had not effect on their stimulatory capacity. These results substantiate the conclusion that P388D1 cells must internalize and probably catabolize PPD to form the relevant antigenic determinant. A20 cells, on the other hand, may not need to internalize PPD to form the determinant recognized by the $T$ cells.

Since A20 cells apparently did not require PPD internalization for stimulation, it was important to determine if T-cell stimulation could be produced with isolated A20 plasma membranes. In the past, isolated membranes alone have not directly stimulated $\mathrm{T}$ cells and always required reprocessing by APC in the culture. To our surprise, we found that isolated plasma membranes from A20 cells failed to stimulate the T hybridomas in the presence of PPD (Table 5). However, the membranes from PPDpulsed A20 cells successfully stimulated T hybridomas in the absence of soluble PPD and any other stimulator cells. In titration experiments it was found that almost 10 times as many cell equivalents of membranes as intact $\Lambda 20$ cells were required to obtain the same level of IL-2 production (data not shown). It should also be noted that addition of soluble PPD to the mixture of $T$ hybridomas and membranes from PPD-pulsed A20 cells did not enhance the stimulation. The stimulation of the PPDspecific $T$ hybridomas by the membranes was also specific for PPD since membranes from untreated A20 cells or from A20 cells that were pulsed with another antigen ( $N$-hydroxysuccinimidyl-4-azidobenzoate) failed to stimulate the PPD-specific $\mathrm{T}$ hybrdiomas (data not shown). Stimulation of $\mathrm{T}$ hybridomas by plasma membranes from PPD-pulsed A20 cells was also restricted by $I-A^{d}$, and the $T$ cell responses were effectively blocked by addition of anti-Ia ${ }^{\mathrm{d}}$ monoclonal antibody, M5/114.15.2 (19), to the mixture of T hybridoma and PPD-pulsed plasma membranes, as shown in Table 6. As a control, the anti-Ia ${ }^{k}$ monoclonal antibody, 10.2.16 (20), gave no significant inhibition of the $\mathrm{T}$ hybridoma response. Thus, antigen-specific $\mathrm{T}$-cell stimulation by

TABLE 4

Ability of Chloroquine-Treated Cells to Stimulate T Hybridoma Cells

\begin{tabular}{lccc}
\hline & \multicolumn{3}{c}{ IL-2 units/ml } \\
\cline { 2 - 4 } & \multicolumn{2}{c}{ Chloroquine treatment } \\
\cline { 2 - 4 } \multicolumn{1}{c}{ Cell type } & $\begin{array}{c}\text { Before PPD } \\
\text { pulsing }^{a}\end{array}$ & $\begin{array}{c}\text { After PPD } \\
\text { pulsing }\end{array}$ & $\begin{array}{c}\text { No } \\
\text { treatment }\end{array}$ \\
\hline A20 & 640 & 640 & 640 \\
la-positive P388D1 & 80 & 320 & 640 \\
\hline
\end{tabular}

${ }^{a}$ A20 or Ia-positive P388D1 cells were incubated at $37^{\circ} \mathrm{C}$ with $600 \mu M$ chloroquine for 45 min, washed, and then incubated with $200 \mu \mathrm{g} / \mathrm{ml}$ PPD for $2 \mathrm{hr}$ at $37^{\circ} \mathrm{C}$, washed, and added to $\mathrm{I}$ hybridomas for stimulation.

${ }^{b}$ A20 or Ia-positive P388D1 cells were incubated with $200 \mu \mathrm{g} / \mathrm{ml}$ of PPD for $2 \mathrm{hr}$ at $37^{\circ} \mathrm{C}$, washed, and then incubated with $600 \mu M$ chloroquine for $45 \mathrm{~min}$ at $37^{\circ} \mathrm{C}$, washed, and added to $\mathrm{T}$ hybridomas for stimulation. 
TABLE 5

Comparison of the Ability of Plasma Membranes from Antigen-Pulsed A20.2JAD and from Non-antigen-Pulsed A20.2JAD to Stimulate T Hybridoma Cells

\begin{tabular}{ccc}
\hline $\begin{array}{c}\text { Source of } \\
\text { plasma membranes }\end{array}$ & $\begin{array}{c}\text { Presence of } \\
\text { PPD }\end{array}$ & IL-2 units/ml \\
\hline Untreated A20.2JAD & - & $<20$ \\
& + & $<20$ \\
PPD-pulsed A20.2JAD & - & 640 \\
& + & 640 \\
\hline
\end{tabular}

${ }^{a}$ Plasma membranes $\left(3 \times 10^{6}\right.$ cell equivalents) prepared from PPD-pulsed or non-antigen-pulsed A20 cells were cultured with the PPD-specific T hybridoma cells with or without $10 \mu \mathrm{g}$ soluble PPD, and the IL-2 responses were determined as described under Materials and Methods.

isolated plasma membranes is regulated by Ia antigens similar to stimulation by intact antigen-presenting cells.

One of the puzzling features of the T-cell stimulation by isolated membranes is that addition of soluble PPD to membranes from non-antigen-pulsed A20 cells failed to stimulate. Since PPD added to glutaraldehyde-fixed A20 cells resulted in excellent T-cell responses, we anticipated that membranes with added PPD would be stimulatory. The first possibility we considered was that the membranes failed to proteolytically process PPD, perhaps since PMSF was included in the isolation buffer that would have blocked some proteases. We therefore prepared membranes in the absence of PMSF, but they too failed to stimulate T cells when soluble PPD was added. In other approaches, we predigested PPD with trypsin, chymotrypsin, and supernatant fluids from A20 cell cultures, then added the digested PPD to membranes and T cells, but no stimulation was observed. Supernatant fluids from A20 cells cultured with PPD, and presumably containing processed PPD, were also tried without success. In addition, NP-40-solubilized extracts of the PPD-pulsed A20 membranes were also nonstimulatory, even in the presence of intact A20 cells. We therefore conclude that the membrane preparation disrupts some processing elements, or that molecular associations between processed PPD and other membrane structures does not occur after the A20 cells are disrupted. Thus, while presentation of PPD does not seem to require internalization by $\mathrm{A} 20$ cells, the integrity of the plasma membrane is critical for presentation.

TABLE 6

Effect of Anti-Ia Antibodies on the Ability of Antigen-Pulsed Plasma Membranes to Stimulate T Hybridoma Cells

\begin{tabular}{lc}
\hline \multicolumn{1}{c}{ Antibody $^{a}$} & IL-2 units/ml \\
\hline None & 640 \\
Anti-Ia $^{\mathrm{k}}(10.2 .16)$ & 320 \\
Anti-Ia $^{\mathrm{d}}(\mathrm{M} 5 / 114.15 .2)$ & $<20$ \\
\hline
\end{tabular}

\footnotetext{
${ }^{a}$ Anti-la antibodies (20\% final volume of monoclonal antibody-containing supernatant fluids) were added to cultures of PPD-specific T hybridoma cells and plasma membranes $\left(2 \times 10^{6}\right.$ cell equivalents) from PPDpulsed A20.2JAD cells, and the IL-2 responses were determined as described under Materials and Methods.
} 


\section{DISCUSSION}

Many reports have described an antigen-processing event that apparently involves the internalization and catabolism of protein antigens. Thus, antigen-presenting cells fixed with glutaraldehyde or paraformaldehyde fail to present protein antigens for T-cell activation unless the protein is first digested to a smaller antigenic fragment $(1,2)$. In this report we have shown that protein antigen presented to the same $\mathrm{T}$ cells by two different presenting cells shows different pathways in forming the antigenic determinant. According to the interpretation that sensitivity to glutaraldehyde fixation indicates a requirement for antigen internalization, this would suggest that the processing of PPD by P388D1 cells involves internalization, whereas processing by A20 cells does not. This conclusion was substantiated by the finding that chloroquine inhibited antigen processing by $\mathrm{P} 388 \mathrm{D} 1$ cells, presumably by inhibiting lysosomal catabolism $(14,15)$, but had no effect on antigen presentation by A20 cells. Thus, the processing pathway by P388D1 cells is similar to that described in other systems (1-5) that indicate that protein antigens are internalized and degraded by lysosomal enzymes to produce antigenic peptide fragments that become associated with the plasma membrane. This latter point was substantiated by finding that glutaraldchydc treatment of P388D1 cells after PPD pulsing had no inhibitory effect indicating that the relevant antigenic moiety was displayed on the cell surface, consistent with similar results by others $(1,2)$.

By contrast with the results described above for the antigen processing by P388D1 cells, PPD presentation by A20 cells was not impaired by glutaraldehyde fixation and chloroquine treatment. These results indicate that A20 cells process and present PPD by a pathway that is different from that utilized by P388D1 cells. However, the same antigenic determinant must be produced by both cellular processing pathways since only a single determinant is recognized by the monoclonal $\mathrm{T}$ cell. The implications of these results with A20 cells are that either (i) PPD requires no processing for presentation to $T$ cells, as suggested in a recent report by Kaye et al. (16), or (ii) A20 cells can process PPD via a membrane-bound mechanism. Assuming that processing is required for presentation of $P P D$, as indicated by the results with $P 388 D 1$, the most likely possibility is that in A20 cells the moieties responsible for processing of PPD are located in the plasma membrane. Since the major processing event appears to be antigen catabolism to smaller peptide fragments, it is likely that this results from a membrane-bound protease. Thereby the relevant antigenic peptide results from proteolysis by an enzyme, or enzymes, that are associated with the A20 membrane, but are internal (lysosomal) in P388D1 cells. This indicates that there are several different cellular processing pathways that can be used to create the relevant antigen from a larger protein. These mechanisms may vary from one to another type of antigenpresenting cell for formation of the same antigenic determinants, and potentially could also serve to create antigenic determinants from foreign proteins that are unique for each antigen-presenting cell type, as previously suggested (17). It should be pointed out, however, that these results may be unique to the PPD system examined here, and may not be generally applicable to all protein antigens and APC.

As indicated before, the fact that glutaraldehyde-treated A20 cells could still present PPD to $T$ hybridomas was an indication that it may be possible to achieve stimulation with isolated plasma membranes. Indeed, it was found that membranes from PPDpulsed A20 cells were competent to stimulate T hybridoma cells, and that this stim- 
ulation involved antigen and class II MHC antigens as does stimulation by intact cells. In most systems it has been possible to achieve stimulation by isolated membranes only in the presence of viable APC, which has been interpreted as an indication that the membranes were being reprocessed by APC for T-cell presentation. Clearly this is not the case in the membrane stimulation described in this report since no stimulator cells are present with the T hybridoma cells, which themselves fail to present PPD and do not express class II MHC antigens (unpublished observations). Very recently, however, Watts et al. (18) have shown that purified class II MHC antigens incorporated into synthetic planar membranes will stimulate $T$ hybridomas in the presence of large amounts of soluble antigen. In this sytem the observed stimulation was relatively weak, and they did not determine if antigen pulsing of the planar membranes could stimulate the $T$ cells. Another feature to point out is that in our hands antigen-pulsed membranes do not stimulate in all antigen specific T-cell hybridoma systems we have examined, and thus far is most efficient with the PPD-specific T hybrid described here. One of the puzzling aspects of the results described above is that glutaraldehydetreated A20 cells can present PPD, whereas addition of PPD to isolated membranes and $T$ cells is nonantigenic. One would anticipate that if PPD-processing by A20 cells is a membrane-associated event, then isolated plasma membranes would bc ablc to process and present PPD. It was observed, however, that only membranes from PPDpulsed A20 cells would stimulate T cells. Attempts were made to preprocess the PPD before adding it to culture with A20 membranes, but all of these were unsuccessful. The simplest explanation for this is that the processing moieties are destroyed during the membrane isolation procedure. Alternatively, the processing system could exist as a multimolecular complex that is disrupted during isolation. Experiments to investigate these possibilities are currently in progress.

In summary, the results reported here show that two different antigen-presenting cells differ in the cellular location of the antigen processing event required for T-cell antigen recognition of the protein antigen PPD. This is an observation with important implications for the ability of different cells to act as antigen-presenting cells, and raises the possibility that different antigen-presenting cell types can produce unique peptide antigens from a larger protein which may selectively activate distinct T-cell subpopulations. At this time it is not yet known if this applies to all protein antigens, or is unique to the PPD system examined here. The second important observation reported here is the ability of isolated plasma cell membranes from antigen-pulsed APC to directly stimulate T cells. This is the first report of direct T-cell stimulation by isolated antigen-pulsed membranes in the clear absence of stimulator cells, to our knowledge, and thereby provides a starting point to more carefully define the formation of the antigenic determinants specifically recognized by $\mathrm{T}$ cells.

\section{ACKNOWLEDGMENT}

The authors thank Ms. Emma Williams for the excellent typing of this manuscript.

\section{REFERENCES}

1. Shimonkevitz, R., Kappler, J., Marrack, P., and Grey, H., J. Exp. Med. 158, 303, 1983.

2. Allen, P. M., Beller, D. I., Braun, J., and Unanue, E. R., J. Immunol. 132, 323, 1984.

3. Ziegler, H. K., and Unanue, E. R., Proc. Natl. Acad. Sci. USA 79, 175, 1982.

4. Allen, P. M., Strydom, D. J., and Unanue, E. R., Proc. Natl. Acad. Sci. USA 81, 2489, 1984. 
5. Shimonkevitz, R., Colon, S., Kappler, J. W., Marrack, P., and Grey, H. M., J. Immunol. 133, 2067, 1984.

6. Thomas, D. W., J. Immunol. 121, 1760, 1978.

7. Nairn, R., Spengler, M. L., Hoffman, M. D., Solvay, M. J., and Thomas, D. W., J. Immunol. 133, 3225, 1984.

8. Kappler, J. W., Skidmore, B., White, J., and Marrack, P., J. Exp. Med. 153, 1198, 1981.

9. Glimcher, L. H., and Shevach, E. M., J. Exp. Med. 156, 640, 1982.

10. Mishell, R. I., and Dutton, R. W., J. Exp. Med. 126, 423, 1967.

11. Zlotnik, A., Shimonkevitz, R. P., Gefter, M. L., Kappler, J., and Marrack, P., J. Immunol. 131, 2814, 1983.

12. Streicher, H. Z., Berkower, I. J., Busch, M., Gurd, F. R. N., and Berzofsky, J. A., Proc. Natl. Acad. Sci. USA 81, 6831, 1984.

13. Shimonkevitz, R., Kappler, J., Marrack, P., and Grey, H., J. Exp. Med. 158, 303, 1983.

14. Ohkuma, S., and Poole, B., Proc. Natl. Acad. Sci. USA 75, 3327, 1978.

15. Hopgood, M. F., Clark, M. G., and Ballard, F. J., Biochem. J. 164, 399, 1977.

16. Kaye, P. M., Chain, B. M., and Feldmann, M., J. Immunol. 134, 1930, 1985.

17. Peterson, L. B., Wilner, G. D., and Thomas, D. W., J. Immunol. 130, 2542, 1983.

18. Watts, T. H., Brian, A. A., Kappler, J. W., Marrack, P., and McConnell, H. M., Proc. Natl. Acad. Sci. USA 81, 6159, 1984.

19. Bhattacharya, A., Dorf, M. E., and Springer, T. A., J. Immunol. 127, 2488, 1981.

20. Oi, V. T., Jones, P. P., Goding, J. W., Herzenberg, L. A., and Herzenberg, L. A., Curr. Top. Microbiol. Immunol. 81, 115, 1978. 